\title{
Corticosteroid treatment in severe COVID-19 pneumonia: two cases and literature review
}

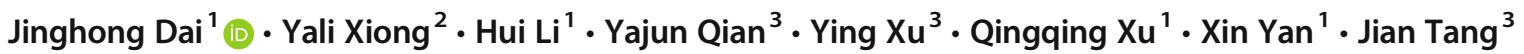

Received: 21 April 2020 / Revised: 5 May 2020 / Accepted: 15 May 2020 / Published online: 25 May 2020

(C) International League of Associations for Rheumatology (ILAR) 2020

\begin{abstract}
Coronavirus disease 2019 (COVID-19) pneumonia, firstly reported in Wuhan, Hubei province, China, has rapidly spread around the world with high mortality rate among critically ill patients. The use of corticosteroids in COVID-19 remains a major controversy. Available evidences are inconclusive. According to WHO guidance, corticosteroids are not recommended to be used unless for another reason. Chinese Thoracic Society (CTS) proposes an expert consensus statement that suggests taking a prudent attitude of corticosteroid usage. In our clinical practice, we do not use corticosteroids routinely; only low-to-moderate doses of corticosteroids were given to several severely ill patients prudently. In this paper, we will present two confirmed severe COVID-19 cases admitted to isolation wards in Optical Valley Campus of Tongji hospital, Tongji Medical College, Huazhong University of Science and Technology. We will discuss questions related to corticosteroids usages.
\end{abstract}

Keywords Corticosteroids $\cdot$ COVID-19 $\cdot$ HRCT $\cdot$ Severe COVID-19 pneumonia

\section{Introduction}

The use of corticosteroids in coronavirus disease 2019 (COVID-19) pneumonia remains a major controversy. According to WHO guidance, corticosteroids are not recommended to be used routinely for patients with severe acute respiratory infection when 2019-nCoV infection is suspected, unless indicated for another reason [1]. In spite of this, from the point of urgently clinical demand, Chinese Thoracic Society (CTS) proposed an expert consensus statement that suggests taking a prudent attitude of corticosteroids usage [2]. The following criteria should be considered [3]: (1) the benefits and harms should be carefully weighed before using

Jinghong Dai

daijinghong@nju.edu.cn

1 Department of Pulmonary and Critical Care Medicine, Nanjing Drum Tower Hospital, The Affiliated Hospital of Nanjing University Medical School, Zhongshan Road 321, Nanjing 210008, Jiangsu, China

2 Department of Infectious Diseases, Nanjing Drum Tower Hospital, The Affiliated Hospital of Nanjing University Medical School, Nanjing 210008, China

3 Department of Intensive Care Unit, Nanjing Drum Tower Hospital, The Affiliated Hospital of Nanjing University Medical School, Nanjing 210008, China corticosteroids; (2) corticosteroids should be used prudently on critically ill patients; (3) for patients with hypoxemia due to underlying diseases or who use corticosteroids for chronic diseases on a regular basis, further use of corticosteroids should be cautious; (4) the dosage should be low to moderate $(\leq 0 \cdot 5-1 \mathrm{mg} / \mathrm{kg}$ per day methylprednisolone or equivalent) and the duration should be short ( $\leq 7$ days).

In clinical practices, several questions still exist. For example, who is most likely to benefit from corticosteroid usages? When should we consider to take corticosteroids intervene? Which dosages or durations are appropriate? As a front-line physician, I worked for about 2 months in Optical Valley Campus of Tongji hospital, Tongji Medical College, Huazhong University of Science and Technology. My colleagues and I did not use corticosteroids routinely. A total of 92 patients with severe COVID-19 pneumonia were treated in our ward. Among them, low-to-moderate doses of corticosteroids were only given to seven patients prudently at different stages in the disease course. Most of them showed favorable response to corticosteroid treatment with improvement of clinical syndromes and HRCT findings. In the following sections, we present two representative confirmed severe COVID-19 cases according to $\mathrm{WHO}$ interim guidance [1] who have received corticosteroid treatment during their hospitalization. Relevant questions about corticosteroid usages are also discussed. 


\section{Case description}

The two patients are residents of Wuhan City and both had exposure to patients with confirmed severe COVID-19.

\section{Case 1}

A 41-year-old man with no smoking history was admitted on February 11, and the duration from onset of syndromes to admission was 5 days. He was from a family clustering of COVID-19 and his parents and grandmother died from COVID-19. He presented dyspnea and fever with maximum body temperature of $40.0^{\circ} \mathrm{C}$. He reported poor appetite without diarrhea and had chronic sinusitis.

Laboratory tests results and treatment information are demonstrated in Tables 1 and 2. The patient had leukocytopenia with lymphocytopenia and had an increased C-reaction protein (CRP) and interleukin (IL)-6. He received antiviral treatment including arbidol, hydroxychloroquine, and ribavirin. Wide-spectrum antibiotics (moxifloxacin and imipenem) were used to prevent secondary infections. Other therapies included relieve coughing and phlegm, immunomodulatory, antioxidant, and nutritional support. At admission, he required high-flow oxygen therapy (flow rate $10 \mathrm{~L} /$ Min) through a face mask, and his pulse oxygen saturation was $90 \%$. He did not receive mechanic ventilation or noninvasive ventilation during hospitalization.

The first day after his admission, the fever persisted, and dry cough and dyspnea worsened. Chest high-resolution computed scan (HRCT) was performed and showed a rapid progression of diffuse ground-glass opacities (GGO) and consolidations compared to those performed before admission. Methylprednisolone (40 mg twice daily, intravenously) was administered for 4 days and then discontinued. After corticosteroids were given, his body temperature decreased to normal and the syndromes improved. HRCT showed obvious absorption of GGO and consolidations (Fig. 1). By March 26, 2020, he was discharged.

Table 1 Demographics, clinical characteristics, and treatment of the two patients with severe COVID-19 pneumonia on admission to hospital

\begin{tabular}{|c|c|c|}
\hline & Patient 1 & Patient 2 \\
\hline Sex, F/M & M & M \\
\hline Age, years & 41 & 73 \\
\hline Smoking history & None & None \\
\hline Basic disease & Chronic sinusitis & None \\
\hline Date at onset of symptoms & $2020 \mathrm{Feb} 06$ & 2020 Jan 28 \\
\hline Admission date & 2020 Feb 11 & $\begin{array}{l}2020 \mathrm{Feb} 08 \text { (admitted to other hospital) } \\
2020 \mathrm{Feb} 23 \text { (transferred to our hospital) }\end{array}$ \\
\hline Days from onset to admission, days & 5 & 10 \\
\hline Days from onset to using corticosteroid, days & 9 & 26 \\
\hline Length of hospital stay, days & 46 & Still in hospital \\
\hline Highest temperature, ${ }^{\circ} \mathrm{C}$ & 40.0 & 40.0 \\
\hline \multicolumn{3}{|l|}{ Presented symptoms } \\
\hline Fever & + & + \\
\hline Cough & - & + \\
\hline Dyspnea & + & + \\
\hline Diarrhea & - & - \\
\hline Poor appetite & + & + \\
\hline \multicolumn{3}{|l|}{ Therapy } \\
\hline Antiviral therapy & Arbidol, hydroxychloroquine, ribavirin & Hydroxychloroquine, ribavirin \\
\hline Antibiotic therapy & Moxifloxacin, imipenem & Meropenem \\
\hline Antioxidant therapy & Acetylcysteine & Acetylcysteine \\
\hline Anticoagulant therapy & None & Low molecular weight heparin, rivaroxaban \\
\hline Nutrition support & $\begin{array}{l}\text { Nutrison, enteral nutritional suspension } \\
\text { (TP-MCT) }\end{array}$ & Nutrison \\
\hline Immunoregulator & Gamma globulin, thymopentin & Gamma globulin, thymopentin \\
\hline Use of corticosteroid & Methylprednisolone $40 \mathrm{mg}$ qd for 4 days & $\begin{array}{l}\text { Methylprednisolone } 40 \mathrm{mg} \text { bid for } 5 \text { days, then } \\
40 \mathrm{mg} \text { qd for } 3 \text { days, then } 16 \mathrm{mg} \text { qd for } 4 \text { days, } \\
12 \mathrm{mg} \text { qd for } 4 \text { days, } 8 \mathrm{mg} \text { qd for } 9 \text { days }\end{array}$ \\
\hline
\end{tabular}


Table. 2 Laboratory findings of the two patients with severe COVID-19 pneumonia on admission to hospital

\begin{tabular}{|c|c|c|}
\hline & Patient 1 & Patient 2 \\
\hline \multicolumn{3}{|l|}{ Blood routine } \\
\hline White blood cell count $(* 109 / \mathrm{L}, 3.5 \sim 9.5)$ & 3.01 & 12.13 \\
\hline Neutrophils (*109/L, 1.8 6.3) & 1.52 & 10.61 \\
\hline Neutrophils percent $(\%, 40.0 \sim 75.0)$ & 50.5 & 87.3 \\
\hline Lymphocytes $(* 109 / \mathrm{L}, 1.1 \sim 3.2)$ & 1.05 & 0.67 \\
\hline Lymphocytes percent $(\%, 20.0 \sim 50.0)$ & 34.9 & 5.5 \\
\hline \multicolumn{3}{|l|}{ Blood biochemistry } \\
\hline Alanine aminotransferase $(\mathrm{U} / \mathrm{L}, \leq 41)$ & 18 & 12 \\
\hline Aspartate aminotransferase $(\mathrm{U} / \mathrm{L}, \leq 40)$ & 41 & 12 \\
\hline Creatinine $(\mu \mathrm{mol} / \mathrm{L}, 59 \sim 104)$ & 67 & 51 \\
\hline Urea $(\mathrm{mmol} / \mathrm{L}, 3.6 \sim 9.5)$ & 4.20 & 4.10 \\
\hline Lactate dehydrogenase (U/L, 135 225) & 297 & 317 \\
\hline Albumin $(\mathrm{g} / \mathrm{L}, 35 \sim 52)$ & 37.4 & 39.6 \\
\hline Globulin (g/L, 20 35) & 24.6 & 32.5 \\
\hline \multicolumn{3}{|l|}{ Infection-related biomarkers } \\
\hline Procalcitonin (ng/mL, 0.02 0.05) & 0.08 & 0.10 \\
\hline \multicolumn{3}{|l|}{ C-reactive protein $(\mathrm{mg} / \mathrm{L},<1 \mathrm{mg} / \mathrm{L})$} \\
\hline Prior to prednisolone $40 \mathrm{mg}$ bid & 7.9 & 139.3 \\
\hline 2nd day after treatment & 54.1 & - \\
\hline 4th day after treatment & 3 & 8 \\
\hline $\mathrm{TNF}-\alpha(\mathrm{pg} / \mathrm{ml},<8.1)$ & 5.8 & 9.1 \\
\hline Interleukin-1 $\beta(\mathrm{pg} / \mathrm{ml},<5.0)$ & $<5.0$ & 51.0 \\
\hline \multicolumn{3}{|l|}{ Interleukin-6 (pg/ml, <7.0) } \\
\hline Prior to prednisolone $40 \mathrm{mg}$ bid & 66.23 & 139.00 \\
\hline After treatment & 3.18 (Day 22) & 3.39 (Day 20) \\
\hline \multicolumn{3}{|l|}{ Coagulation function } \\
\hline D-dimer $(\mu \mathrm{g} / \mathrm{ml} \mathrm{FEU},<0.5)$ & 0.22 & 2.65 \\
\hline Prothrombin time (s, 11.5 14.5) & 13.3 & 14.6 \\
\hline Activated partial thromboplastin time (s, 29.0 42.0) & 45.2 & 39.0 \\
\hline \multicolumn{3}{|l|}{ AMI indexes } \\
\hline Creatine kinase, MB Form $(\mathrm{ng} / \mathrm{mL}, \leq 7.2)$ & 1.1 & 1.2 \\
\hline Cardiac troponin I (pg/mL, $\leq 34.2)$ & 4.5 & 4.0 \\
\hline Myoglobin $(\mathrm{ng} / \mathrm{mL}, \leq 154.9)$ & 95.9 & 23.4 \\
\hline$N$-terminal pro-B-type natriuretic peptide $(\mathrm{pg} / \mathrm{mL},<241)$ & 849 & 414 \\
\hline Partial pressure of oxygen $(\mathrm{mmHg}, 80 \sim 100)$ & 79.0 & 78.8 \\
\hline Oxygen saturation $(\%, 95 \sim 99)$ & $93(10 \mathrm{~L} / \mathrm{min})$ & $96(10 \mathrm{~L} / \mathrm{min})$ \\
\hline Confirmed date by real-time RT-PCR & 2020 Feb 11 & 2020 Feb 07 \\
\hline
\end{tabular}

\section{Case 2}

A 73-year-old man with no smoking history was admitted to another hospital on February 8, 2020 and the duration from onset of syndromes to admission was 10 days. He stayed in that hospital for 15 days with persistent fever and worsening dyspnea, then transferred to our hospital on February 23, 2020. He also presented dyspnea, dry cough, and fever with maximum body temperature of $40.0{ }^{\circ} \mathrm{C}$. He reported poor appetite without diarrhea and denied having any chronic diseases.
The patient had an increased count of white blood cell, an increased CRP, and an elevated D-Dimer. The concentrations of tumor necrosis factor (TNF)- $\alpha$, IL- $1 \beta$, and IL- 6 were elevated. The antiviral treatments he received were similar to case 1 except for arbidol. Meropenem was used to prevent secondary infections. At admission, he required high-flow oxygen therapy and his pulse oxygen saturation was $95 \%$.

The fever persisted, and dry cough and dyspnea worsened on the first day after his admission. HRCT was performed, showing diffused GGO and a subpleural consolidation with air trapped in the left upper lung. The initial dosage of 


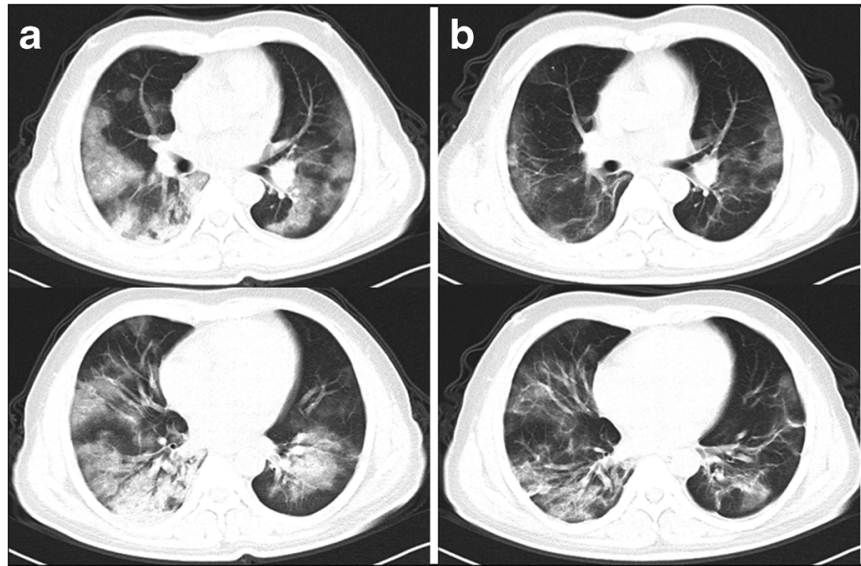

Fig. 1 Serial HRCT findings in patient 1. a At admission (2020 Feb 16), chest high-resolution computed scan (HRCT) showed bilateral diffused ground-glass opacities (GGO) and consolidation. b After using corticosteroids for 3 days (2020 Feb 19), HRCT showed an obvious

methylprednisolone was $40 \mathrm{mg}$ twice daily for 3 days, then tapered to $40 \mathrm{mg}$ per day for 3 days; after that, oral dosage was maintained 8 16 mg per day for 14-17 days and discontinued. After giving him corticosteroids, the syndromes improved and HRCT showed an improved status (Fig. 2). By March 29, 2020, he was still hospitalized.

\section{Review and discussion}

The treatment of COVID-19 is a great challenge for clinicians and no pharmacological therapy has been proven effective yet. The mainstay of treatment is supportive care. Clark Russell and his colleagues [4] summarized the available clinical evidence on corticosteroid therapy in severe COVID-19 [5], Middle East respiratory syndrome (MERS) [6] and influenza

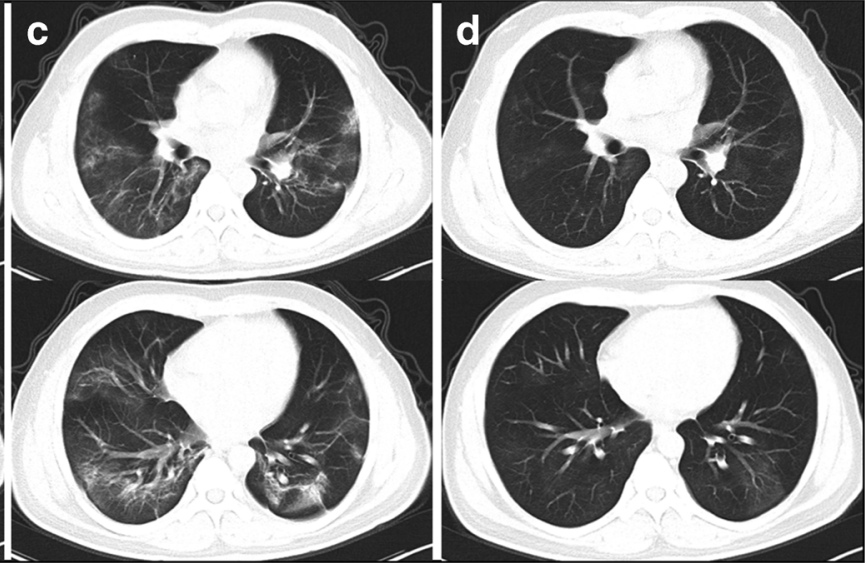

absorption of GGO and consolidations. c Eight days after using corticosteroids (2020 Feb 24), HRCT showed a further improved status. d One month later (2020 Mar 17), HRCT showed the abnormalities were absorbed mostly with a little GGO left in the left lower lung

[7] against corticosteroid use in 2019 novel coronavirus pneumonia, except in the setting of a clinical trial. The main potential risks associated with corticosteroids usage include secondary infections, long-term complications, and delayed virus clearance. In addition, the administration of corticosteroids did not show an advantage to decrease mortality [7], plus, patients receiving corticosteroids were more likely to require mechanical ventilation, vasopressors, renal replacement therapy and stay in intensive care unit (ICU) longer [6].

On the other hand, several studies supported the use of corticosteroids at low-to-moderate doses in patients with virus infection. Reports showed that the proper use of corticosteroids could reduce the mortality of critically ill SARS patients and shorten their hospital stay without causing secondary infections and other complications [8]. Furthermore, low-tomoderate doses of corticosteroids were also associated with

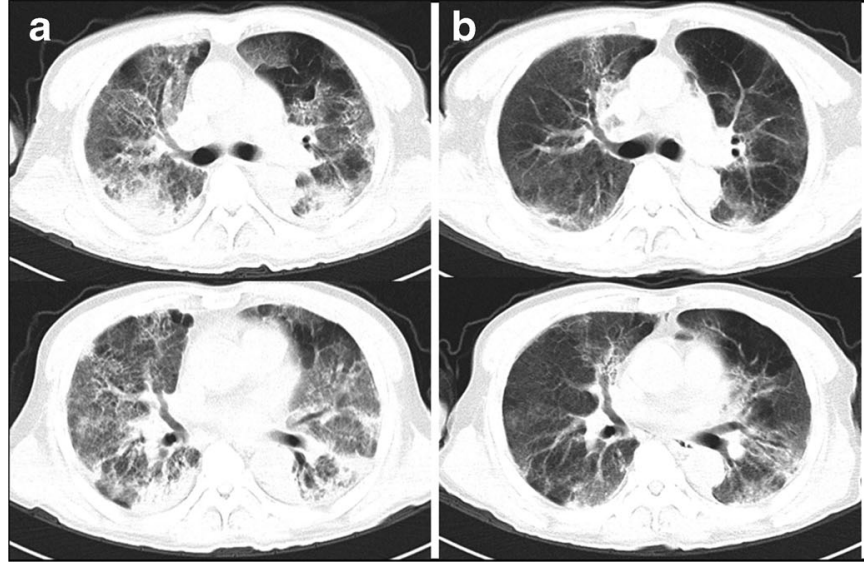

Fig. 2 Serial HRCT findings in patient 2. a The 3rd day from admission (2020 Feb 23), chest high-resolution computed scan (HRCT) showed diffused ground-glass opacities (GGO) and a subpleural consolidation, and air trapping in the left upper lung. b After using corticosteroids for 6 days (2020-02-29), HRCT showed an obvious absorption of

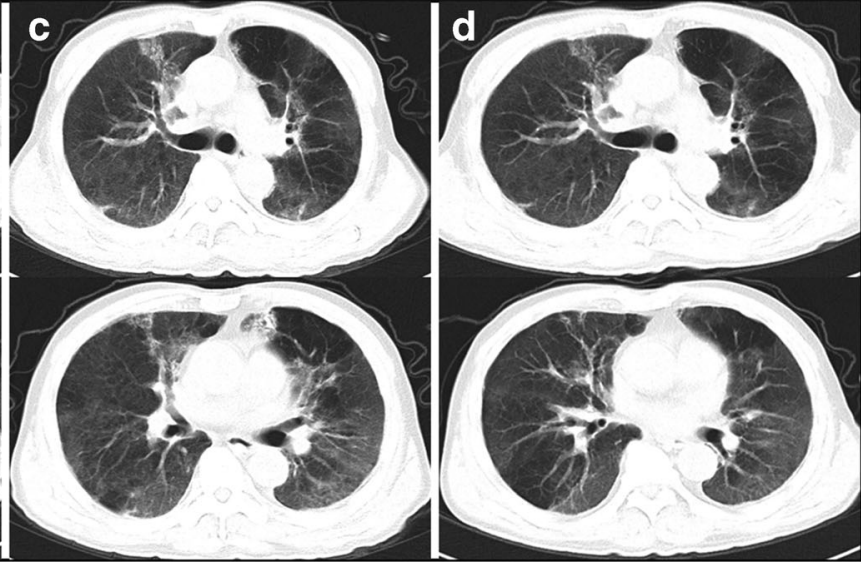

consolidation with mild diffused GGO and a little consolidation with subpleural distribution. c Fourteen days later (2020 Mar 08), HRCT showed patchy consolidation in the upper lung and the left upper lung. d Twenty-four days later (2020 Mar 17), HRCT showed mild diffused mild GGO and air trapping in the left upper lung and right lower lung 
reduced mortality in patients with influenza A (H1N1) viral pneumonia when oxygen index was lower than $300 \mathrm{mmHg}$ [9]. Recently, Song et al. reported that methylprednisolone treatment might be beneficial for patients with COVID-19 who developed acute respiratory distress syndrome (ARDS) [10].

The clinical course of COVID-19 is not to be fully characterized. Zhang et al. [11] reported that about $17 \%$ of patients with severe illness may quickly progress to ARDS. Among them, $11 \%$ of patients worsened in 1 2 weeks and died of multiple organ failure. In our cases, patient 1 was admitted on the fifth day from onset. The disease course and chest HRCT abnormalities progressed rapidly. A study reported that the pathological findings of COVID-19 were interstitial mononuclear inflammatory infiltrating, pulmonary edema, and hyaline membrane formation, suggesting early phase of ARDS. So, timely and appropriate use of corticosteroids could be considered to attenuate cytokine-related lung injury and prevent ARDS development [12]. For patient 2, when he was transferred to our hospital, the clinical course was exceeding 20 days and HRCT showed a prominent consolidation with bilateral involvement. The clinical characteristics, disease course, and radiological findings demonstrated a subacute process, resembling secondary organizing pneumonia (SOP) [13]. The total durance of corticosteroids was 25 days and he showed a favorable response to corticosteroid treatment. However, is the treatment durance appropriate? Do such "organizing pneumonia"-like abnormalities in HRCT progress or relapse after corticosteroids discontinued? What extent or degree will the interstitial abnormalities be left in the lung? How long will it take for lung functions to recover? All these clinical questions remain our concerns. A long-term follow up is indeed needed to monitor the serial pulmonary functions and HRCT appearances.

Cytokine release syndrome (CRS) contributing to multiorgan dysfunctions has been widely discussed in the pathogenesis of COVID-19 for the plasma levels of proinflammatory cytokines, particularly IL-6, IL- $1 \beta$, and TNF- $\alpha$, were markedly increased in ICU patients [14]. Pathogenic T cells and inflammatory monocytes released a considerable amount of interleukin 6 , which was associated with the severity and outcome of the disease and was therefore believed to play a major role in inciting the cytokine storm $[15,16]$. Xu and his colleagues reported 21 cases diagnosed as severe or critical COVID-19 that were treated effectively with tocilizumab, IL-6 receptor antagonist. After being given tocilizumab, the clinical manifestations, HRCT abnormalities, and laboratory examinations remarkably improved and most of the patients were discharged within 2 weeks with no notable adverse reactions observed [17]. Although the evidence came from a single center and the sample size was small, targeting inflammatory signaling pathway is a potential consideration in the treatment of COVID-19 [18]. However,
Radbel J et al. reported two patients progressed to secondary hemophagocytic lymphohistiocytosis (sHLH) despite tocilizumab usage and one developed viral myocarditis [19]. Further randomized controlled trials are still needed to confirm the efficacy and safety and to select patients who could benefit from the treatment of cytokine inhibitors the most.

The mortality rate of critically ill patients with COVID-19 is high, reported beyond $60 \%$ [20]. To reduce the mortality rate, an early warning model must be established to identify severe individuals who are at risk of becoming critically ill. As mentioned in previous studies, older age, a history of cerebrovascular disease, and ARDS were associated with increased risk of death $[11,20,21]$. Sequential Organ Failure Assessment (SOFA) score was associated with death of COVID-19, highlighting the significance of supportive care of organ functions [10, 22]. Lymphocytopenia was also common in critically ill patients with viral infection [23, 24], and careful monitoring of lab examinations is necessary. Other reported biomarkers including PD-1, CTLA4, TIGIT, IFN- $\gamma$, and IL-2, which were associated with functional Tcells, were demonstrated to predict progression of COVID19 [25]. In addition, because fever was not detected during the onset of some patients [26], early or repeated radiological examinations are most important for screening patients with COVID-19 and evaluating disease progression.

\section{Conclusion}

In conclusion, although the controversy in corticosteroid treatment of COVID-19 is heated and existing evidence is inconclusive, arbitrary forbiddance and general recommendation is not advisable. In accordance with CTS expert consensus [2], we suggest the use of low-to-moderate dose of corticosteroids for short courses with caution. Personalized strategy should be rational, and the decision of initiating corticosteroid treatment should be based on the judgment of clinical courses, lab findings, radiological appearances, and, if available, pathological examinations. In addition, it is necessary to detect the associated complications and reexamine chest HRCT in short intervals (within 1 week) to assess treatment response. A welldesigned random controlled study which stratifies patients with disease severity is still needed to treat the disease efficaciously.

Acknowledgments We thank all colleagues at Optical Valley Campus of Tongji hospital, Tongji Medical College, Huazhong University of Science \& Technology.

Authors' contributions Jinghong Dai, Yajun Qian, and Hui Li were the patient's internal medicine physicians. Jinghong Dai wrote the initial draft, did the review of the literature, and edited the manuscript. Jian Tang, Ying $\mathrm{Xu}$, and Qingqing $\mathrm{Xu}$ reviewed and edited the manuscript. 
Yajun Qian and Yali Xiong collected the clinical and HRCT data and edited the manuscript.

Funding information The study was supported by the National Natural Science Foundation of China (81570058), Jiangsu Provincial Medical Talent (ZDRCA2016058), Jiangsu Social Development Project (BE2017604), and the Fundamental Research Funds for the Central Universities (14380460).

\section{Compliance with ethical standards}

Disclosures None.

\section{References}

1. World Health Organization (2020) Clinical management of severe acute respiratory infection when novel coronavirus (nCoV) infection is suspected: interim guidance. https://apps.who.int/iris/handle/ 10665/330893. Accessed 28 Jan 2020

2. Zhao JP, Hu Y, Du RH, Chen ZS, Jin Y, Zhou M, Zhang J, Qu JM, Cao B (2020) Expert consensus on the use of corticosteroid in patients with 2019-nCoV pneumonia. Zhonghua Jie He He Hu Xi Za Zhi 43(3):183-184. https://doi.org/10.3760/cma.j.issn.10010939.2020.03.008

3. Shang L, Zhao J, Hu Y, Du R, Cao B (2020) On the use of corticosteroids for 2019-nCoV pneumonia. Lancet 395(10225):683684. https://doi.org/10.1016/s0140-6736(20)30361-5

4. Russell CD, Millar JE, Baillie JK (2020) Clinical evidence does not support corticosteroid treatment for 2019-nCoV lung injury. Lancet 395(10223):473-475. https://doi.org/10.1016/s0140-6736(20) $30317-2$

5. Stockman LJ, Bellamy R, Garner P (2006) SARS: systematic review of treatment effects. PLoS Med 3(9):e343. https://doi.org/10. 1371/journal.pmed.0030343

6. Arabi YA-O, Mandourah Y, Al-Hameed F, Sindi AA, Almekhlafi GA, Hussein MA, Jose J, Pinto R, Al-Omari A, Kharaba A, Almotairi A, Al Khatib K, Alraddadi B, Shalhoub S, Abdulmomen A, Qushmaq I, Mady A, Solaiman O, Al-Aithan AM, Al-Raddadi R, Ragab A, Balkhy HH, Al Harthy A, Deeb AM, Al Mutairi H, Al-Dawood A, Merson L, Hayden FG, Fowler RA (2018) Corticosteroid therapy for critically ill patients with Middle East respiratory syndrome. Am J Respir Crit Care Med 196(6):757-767. https://doi.org/10.1164/rccm.201706-1172OC

7. Ni YN, Chen G, Sun J, Liang BM, Liang ZA (2019) The effect of corticosteroids on mortality of patients with influenza pneumonia: a systematic review and meta-analysis. Crit Care 23(1):99. https:// doi.org/10.1186/s13054-019-2395-8

8. Chen RC, Tang XP, Tan SY, Liang BL, Wan ZY, Fang JQ, Zhong $\mathrm{N}$ (2006) Treatment of severe acute respiratory syndrome with glucosteroids: the Guangzhou experience. Chest 129(6):14411452. https://doi.org/10.1378/chest.129.6.1441

9. Li H, Yang SG, Gu L, Zhang Y, Yan XX, Liang ZA, Zhang W, Jia HY, Chen W, Liu M, Yu KJ, Xue CX, Hu K, Zou Q, Li LJ, Cao B, Wang C, National Influenza Apdm09 Clinical Investigation Group of C (2017) Effect of low-to-moderate-dose corticosteroids on mortality of hospitalized adolescents and adults with influenza A(H1N1)pdm09 viral pneumonia. Influenza Other Respir Viruses 11(4):345-354. https://doi.org/10.1111/irv.12456

10. Wu C, Chen X, Cai Y, Ja X, Zhou X, Xu S, Huang H, Zhang L, Zhou X, Du C, Zhang Y, Song J, Wang S, Chao Y, Yang Z, Xu J, Zhou X, Chen D, Xiong W, Xu L, Zhou F, Jiang J, Bai C, Zheng J, Song Y (2020) Risk factors associated with acute respiratory distress syndrome and death in patients with coronavirus disease 2019 pneumonia in Wuhan, China. JAMA Int Med. https://doi.org/10. 1001/jamainternmed.2020.0994

11. Chen N, Zhou M, Dong X, Qu J, Gong F, Han Y, Qiu Y, Wang J, Liu Y, Wei Y, Xia Ja YT, Zhang X, Zhang L (2020) Epidemiological and clinical characteristics of 99 cases of 2019 novel coronavirus pneumonia in Wuhan, China: a descriptive study. Lancet 395(10223):507-513. https://doi.org/10.1016/ s0140-6736(20)30211-7

12. Xu Z, Shi L, Wang Y, Zhang J, Huang L, Zhang C, Liu S, Zhao P, Liu H, Zhu L, Tai Y, Bai C, Gao T, Song J, Xia P, Dong J, Zhao J, Wang FS (2020) Pathological findings of COVID-19 associated with acute respiratory distress syndrome. Lancet Respir Med 8: 420-422. https://doi.org/10.1016/S2213-2600(20)30076-X

13. Li HC, Ma J, Zhang H, Cheng Y, Wang X, Hu ZW, Li N, Deng XR, Zhang Y, Zheng XZ, Yang F, Weng HY, Dong JP, Liu JW, Wang YY, Liu XM (2020) Thoughts and practice on the treatment of severe and critical new coronavirus pneumonia. Zhonghua Jie $\mathrm{He}$ He Hu Xi Za Zhi 43(0):E038. https://doi.org/10.3760/cma.j. cn112147-20200312-00320

14. Hirano T, Murakami M (2020) COVID-19: a new virus, but a familiar receptor and cytokine release syndrome. Immunity S1074-7613(20):30161-30168. https://doi.org/10.1016/j.immuni. 2020.04 .003

15. Liu F, Li L, Xu M, Wu J, Luo D, Zhu Y, Li B, Song X, Zhou X (2020) Prognostic value of interleukin-6, C-reactive protein, and procalcitonin in patients with COVID-19. J Clin Virol 127: 104370. https://doi.org/10.1016/j.jcv.2020.104370

16. Conti P, Ronconi G, Caraffa A, Gallenga CE, Ross R, Frydas I, Kritas SK (2020) Induction of pro-inflammatory cytokines (IL-1 and IL-6) and lung inflammation by Coronavirus-19 (COVI-19 or SARS-CoV-2): anti-inflammatory strategies. J Biol Regul Homeost Agents 34(2):1. https://doi.org/10.23812/CONTI-E

17. Xu X, Han MA-O, Li T, Sun W, Wang DA-O, Fu B, Zhou Y, Zheng X, Yang YA-O, Li X, Zhang X, Pan A, Wei H (2020) Effective treatment of severe COVID-19 patients with tocilizumab. Proc Natl Acad Sci U S A 202005615 (1091-6490 (Electronic)). https://doi.org/10.1073/pnas.2005615117

18. Capecchi PA-O, Lazzerini PE, Volterrani L, Mazzei MA, Rossetti B, Zanelli G, Bennett D, Bargagli E, Franchi F, Cameli M, Valente S, Cantarini L, Frediani B (2020) Antirheumatic agents in covid-19: is IL-6 the right target? Ann Rheum Dis:annrheumdis-2020217523. https://doi.org/10.1136/annrheumdis-2020-217523

19. Radbel J, Narayanan N, Bhatt PJ (2020) Use of tocilizumab for COVID-19 infection-induced cytokine release syndrome: a cautionary case report. Chest S0012-3692(20):30764-30769. https:// doi.org/10.1016/j.chest.2020.04.024

20. Yang X, Yu Y, Xu J, Shu H, Ja X, Liu H, Wu Y, Zhang L, Yu Z, Fang M, Yu T, Wang Y, Pan S, Zou X, Yuan S, Shang Y (2020) Clinical course and outcomes of critically ill patients with SARSCoV-2 pneumonia in Wuhan, China: a single-centered, retrospective, observational study. Lancet Respir Med 8:475-481. https:// doi.org/10.1016/s2213-2600(20)30079-5

21. Wang D, Hu B, Hu C, Zhu F, Liu X, Zhang J, Wang B, Xiang H, Cheng Z, Xiong Y, Zhao Y, Li Y, Wang X, Peng Z (2020) Clinical characteristics of 138 hospitalized patients with 2019 novel coronavirus-infected pneumonia in Wuhan, China. JAMA 323(11):1061. https://doi.org/10.1001/jama.2020.1585

22. Zhou F, Yu T, Du R, Fan G, Liu Y, Liu Z, Xiang J, Wang Y, Song B, Gu X, Guan L, Wei Y, Li H, Wu X, Xu J, Tu S, Zhang Y, Chen H, Cao B (2020) Clinical course and risk factors for mortality of adult inpatients with COVID-19 in Wuhan, China: a retrospective cohort study. Lancet 395:1054-1062. https://doi.org/10.1016/ s0140-6736(20)30566-3

23. Liu WJ, Zhao M, Liu K, Xu K, Wong G, Tan W, Gao GF (2017) Tcell immunity of SARS-CoV: implications for vaccine 
development against MERS-CoV. Antivir Res 137:82-92. https:// doi.org/10.1016/j.antiviral.2016.11.006

24. Chu H, Zhou J, Wong BH, Li C, Chan JF, Cheng ZS, Yang D, Wang D, Lee AC, Li C, Yeung ML, Cai JP, Chan IH, Ho WK, To KK, Zheng BJ, Yao Y, Qin C, Yuen KY (2016) Middle East respiratory syndrome coronavirus efficiently infects human primary $\mathrm{T}$ lymphocytes and activates the extrinsic and intrinsic apoptosis pathways. J Infect Dis 213(6):904-914. https://doi.org/10.1093/infdis/ jiv380

25. Zheng H-Y, Zhang M, Yang C-X, Zhang N, Wang X-C, Yang X-P, Dong X-Q, Zheng Y-T (2020) Elevated exhaustion levels and reduced functional diversity of T cells in peripheral blood may predict severe progression in COVID-19 patients. Cell Mol Immunol 17: 541-543. https://doi.org/10.1038/s41423-020-0401-3

26. Holshue ML, DeBolt C, Lindquist S, Lofy KH, Wiesman J, Bruce H, Spitters C, Ericson K, Wilkerson S, Tural A, Diaz G, Cohn A, Fox L, Patel A, Gerber SI, Kim L, Tong S, Lu X, Lindstrom S, Pallansch MA, Weldon WC, Biggs HM, Uyeki TM, Pillai SK (2020) First case of 2019 novel coronavirus in the United States. N Engl J Med 380(10):929-936. https://doi.org/10.1056/ NEJMoa2001191

Publisher's note Springer Nature remains neutral with regard to jurisdictional claims in published maps and institutional affiliations. 